\title{
The Analysis of Stroke Incidence Based on the Multivariate Successive Regression Analysis
}

\author{
Gaofeng Hui ${ }^{1, a}$ \\ ${ }^{1}$ Xi'an Railway Vocational and Technical College, Xi'an, Shaanxi, 710014
}

Keywords: Stroke, MATLAB Programming, Residuals, Multivariate Successive Regression Analysis

\begin{abstract}
Stroke is a common serious threat to human health and life. This article uses multivariate successive regression analysis methods discussed the relationship between incidence and average pressure, pressure difference, average temperature, temperature difference and the average humidity. Through statistical data we obtained the number of cases each year for each month and the incidence of personnel, as well as the number of cases with different gender, age and occupation to obtain a four-year comprehensive monthly temperature data. Finally, summary the results of the etiology of stroke and proposed early warning and intervention programs for high-risk groups.
\end{abstract}

\section{Introduction}

Stroke (commonly known as stroke) is a serious disease that currently threatens human life and its occurrence is a long process, once the disease is difficult to reverse. Induce the disease has been linked to environmental factors, including the presence of a close relationship between air temperature and humidity. Environmental factors on the incidence of stroke were analyzed, its purpose is to conduct a risk assessment of the disease, stroke risk groups to take timely interventions, but also to the health of people not yet sick, or sub-health people have to know their level of risk of stroke to protect themselves. At the same time, through the establishment of a data model, master morbidity of law, for health authorities and medical institutions, medical reasonable allocation of power, improve diagnosis and treatment environment, the configuration of beds and medical drugs and so it has practical significance.

Data (see Appendix-C1) from some city hospitals Chinese stroke patients' information from January 2007 to December 2010 and the corresponding period of local daily meteorological data (Appendix-C2). According to data provided by the subject, carried out on the following issues:

1. Based on the patient's information, statistical description of the incidence of people.

2. Mathematical model of relationship incidence of stroke and air temperature, barometric pressure, relative humidity between.

3. Read and collect documents important features and key indicators related to stroke risk populations, combined with 1 and 2 in the conclusions of the high-risk groups to make recommendations early warning and intervention programs.

\section{The Description of Symbols}

Symbolic
$x_{1}$
$x_{2}$
$x_{3}$
$x_{4}$
$x_{5}$
$y$

Significance

The average monthly air pressure

Monthly air pressure difference

The average monthly temperature

Monthly temperature difference

The average monthly humidity

Monthly incidence 


\section{The Analysis of Problems and Solutions}

Data processing and statistics. In the process of statistical data processing, the use of EXCEL and VB program for statistical data. Due to the large amount of data errors, so we put all the wrong data in accordance with the ratio of the total of valid information is allocated validity of information, reached the following types of statistics.

1, 2007 - 2010, the monthly number of cases and the incidence of personnel statistics are as follows:

\begin{tabular}{|c|c|c|c|c|c|c|c|c|c|c|}
\hline \multirow[b]{2}{*}{ Month } & \multicolumn{2}{|c|}{2007} & \multicolumn{2}{|c|}{2008} & \multicolumn{2}{|c|}{2009} & \multicolumn{2}{|c|}{2010} & \multirow[b]{2}{*}{ Total } & \multirow[b]{2}{*}{ Mean } \\
\hline & Num & Incidence & Num & Incidence & Num & Incidence & Num & Incidence & & \\
\hline Jan & 934 & 0.0705 & 1825 & 0.0958 & 869 & 0.0803 & 1745 & 0.0876 & 5373 & 1343 \\
\hline Feb & 732 & 0.0552 & 1955 & 0.1026 & 847 & 0.0783 & 1798 & 0.0903 & 5332 & 1333 \\
\hline Mar & 1018 & 0.0768 & 1917 & 0.1006 & 789 & 0.0729 & 1725 & 0.0866 & 5449 & 1362 \\
\hline Apr & 1069 & 0.0807 & 1763 & 0.0926 & 860 & 0.0795 & 1700 & 0.0854 & 5392 & 1348 \\
\hline May & 1090 & 0.0822 & 1771 & 0.093 & 871 & 0.0805 & 1887 & 0.0948 & 5619 & 1405 \\
\hline Jun & 1030 & 0.0777 & 1499 & 0.0787 & 792 & 0.0732 & 1614 & 0.081 & 4935 & 1234 \\
\hline Jul & 1013 & 0.0764 & 1496 & 0.0785 & 962 & 0.0889 & 1761 & 0.0884 & 5232 & 1308 \\
\hline Aug & 1196 & 0.0902 & 1372 & 0.072 & 1783 & 0.1648 & 1683 & 0.0845 & 6034 & 1509 \\
\hline Sep & 1221 & 0.0921 & 1280 & 0.0672 & 827 & 0.0764 & 1632 & 0.082 & 4960 & 1240 \\
\hline Oct & 1374 & 0.1037 & 1470 & 0.0772 & 757 & 0.07 & 1722 & 0.0865 & 5323 & 1331 \\
\hline Nov & 1207 & 0.0911 & 1380 & 0.0724 & 664 & 0.0614 & 1568 & 0.0787 & 4819 & 1205 \\
\hline Dec & 1369 & 0.1033 & 1321 & 0.0693 & 797 & 0.0737 & 1079 & 0.0542 & 4566 & 1142 \\
\hline Total & 13253 & & 19049 & & 10818 & & 19914 & & 63034 & \\
\hline
\end{tabular}

2, Different gender (Table 2), different ages (Table 3), different occupations (Table 4) the incidence of statistics as follows:

(1) Annual incidence of different sexes

Table 2

\begin{tabular}{|l|l|l|l|l|l|l|}
\hline Gender & 2007 & 2008 & 2009 & 2010 & Total & Proportion \\
\hline Male & 6571 & 10653 & 5143 & 11025 & 33392 & $53.93 \%$ \\
\hline Female & 5351 & 8857 & 4712 & 9611 & 28531 & $46.07 \%$ \\
\hline
\end{tabular}

(2) Annual incidence of different ages

Table 3

\begin{tabular}{|l|l|l|l|l|l|l|}
\hline Age & 2007 & 2008 & 2009 & 2010 & Total & Proportion \\
\hline $0-44$ & 377 & 563 & 660 & 600 & 2200 & $3.55 \%$ \\
\hline $45-59$ & 1790 & 2806 & 2044 & 2987 & 9627 & $15.55 \%$ \\
\hline $60-74$ & 4744 & 7830 & 3733 & 8032 & 24339 & $39.31 \%$ \\
\hline $75-89$ & 4765 & 7903 & 3278 & 8573 & 24519 & $39.60 \%$ \\
\hline$\geqslant 90$ & 246 & 408 & 140 & 444 & 1238 & $2.00 \%$ \\
\hline
\end{tabular}

(3) Annual incidence of different occupational

Table 4

\begin{tabular}{|l|l|l|l|l|l|l|}
\hline Occupation & 2007 & 2008 & 2009 & 2010 & Total & Proportion \\
\hline Farmer & 8246 & 13338 & 3477 & 14840 & 39901 & $64.44 \%$ \\
\hline Worker & 905 & 1454 & 5039 & 1762 & 9160 & $14.79 \%$ \\
\hline Retirees & 2169 & 3381 & 0 & 2884 & 8434 & $13.62 \%$ \\
\hline Teacher & 44 & 82 & 213 & 61 & 400 & $0.65 \%$ \\
\hline Fisher & 19 & 47 & 28 & 6 & 100 & $0.16 \%$ \\
\hline Medical staff & 25 & 23 & 122 & 16 & 186 & $0.30 \%$ \\
\hline Staff & 56 & 101 & 976 & 386 & 1519 & $2.45 \%$ \\
\hline Retirees & 458 & 1084 & 0 & 681 & 2223 & $3.59 \%$ \\
\hline
\end{tabular}

3 , Based on the statistical results, we got the crowd to stroke the following information:

(1) For different sex, the male is larger than the incidence of women;

(2) for different age groups, the 75-89 year-olds most likely the disease, followed by 60-74 
year-olds;

(3) for different occupations, the highest incidence of farmers, workers, ranking second in the incidence of retirees is higher.

In summary, the results of the incidence of people, mostly elderly, and to focus on the living standards of low farmers, workers and other groups.

Analyze the relationship between the incidence of stroke and air temperature, barometric pressure, and relative humidity.

Through access to information we selected five main indicators, namely the average pressure, pressure difference, the average temperature, temperature, average humidity indicators as the five factors, through the establishment of multiple linear regression model to analyze the average pressure, pressure difference, the average temperature the relationship between temperature, average humidity and disease incidence.

1, Firstly to analyze the relationship between roughly incidence of various environmental factors, we are in the first four years of the first month of the mean pressure summed and then divided by four, the value obtained as the average pressure, the first data that is It represents the average pressure of the first month, whereby the method to calculate the pressure difference per month for four years, data on average temperature, temperature, average humidity is shown in Table 5.

Table 5

\begin{tabular}{|l|l|l|l|l|l|l|l|}
\hline Month & $\begin{array}{l}\text { Average } \\
\text { Pressure }\end{array}$ & $\begin{array}{l}\text { Pressure } \\
\text { difference }\end{array}$ & $\begin{array}{l}\text { Average } \\
\text { temperature }\end{array}$ & $\begin{array}{l}\text { Temperature } \\
\text { difference }\end{array}$ & $\begin{array}{l}\text { Average } \\
\text { humidity }\end{array}$ & $\begin{array}{l}\text { Number of } \\
\text { cases }\end{array}$ & $\begin{array}{l}\text { Disease } \\
\text { incidence }\end{array}$ \\
\hline Jan & 1027.22 & 5.37 & 3.76 & 6.76 & 67.83 & 1343 & 0.0852 \\
\hline Feb & 1022.15 & 5.88 & 6.74 & 7.40 & 70.71 & 1333 & 0.0846 \\
\hline Mar & 1019.23 & 6.38 & 10.35 & 8.15 & 67.25 & 1362 & 0.0864 \\
\hline Apr & 1016.18 & 5.73 & 14.86 & 8.45 & 65.47 & 1348 & 0.0855 \\
\hline May & 1009.71 & 4.52 & 21.59 & 9.39 & 64.42 & 1405 & 0.0891 \\
\hline Jun & 1005.70 & 3.52 & 24.48 & 6.70 & 77.16 & 1234 & 0.0783 \\
\hline Jul & 1003.92 & 3.45 & 29.15 & 7.26 & 73.84 & 1308 & 0.0830 \\
\hline Aug & 1006.03 & 3.48 & 28.89 & 6.94 & 74.89 & 1509 & 0.0957 \\
\hline Sep & 1011.34 & 3.41 & 24.78 & 6.50 & 78.18 & 1240 & 0.0787 \\
\hline Oct & 1018.21 & 3.83 & 19.44 & 7.58 & 73.17 & 1331 & 0.0844 \\
\hline Nov & 1023.17 & 4.49 & 12.17 & 8.02 & 70.98 & 1205 & 0.0765 \\
\hline Dec & 1023.33 & 5.53 & 6.81 & 7.64 & 66.86 & 1142 & 0.0724 \\
\hline
\end{tabular}

2, According to the distribution of data, approximately (quadratic fit), the initial establishment y regression model with the following:

$$
y=b_{1}+b_{2} x_{1}+b_{3} x_{2}+b_{4} x_{3}+b_{5} x_{4}+b_{6} x_{5}+b_{7} x_{2}^{2}+b_{8} x_{4}^{2}+b_{9} x_{5}^{2}
$$

Successive multivariate regression analysis using MATLAB command program (see appendix) to solve the regression coefficient estimates and confidence intervals for the above model (confidence level check), the results of the test statistic in the table below:

Table 6

\begin{tabular}{|c|c|c|}
\hline Parameter & Parameter estimates & Confidence Intervals \\
\hline$b_{1}$ & -3.0459 & {$\left[\begin{array}{ll}-7.8206 & 1.7288\end{array}\right]$} \\
\hline$b_{2}$ & 1.3783 & {$[-0.8687 \quad 3.6252]$} \\
\hline$b_{3}$ & 4.0026 & {$\left[\begin{array}{ll}-4.2724 & 12.2775]\end{array}\right.$} \\
\hline$b_{4}$ & 3.7463 & {$[-0.4289$} \\
\hline$b_{5}$ & -4.0407 & {$\left[\begin{array}{ll}-7.6263 & -0.4550] \\
\end{array}\right.$} \\
\hline$b_{6}$ & 3.4056 & {$[-0.7001 \quad 7.5114]$} \\
\hline$b_{7}$ & -1.6692 & {$[-7.3322$} \\
\hline$b_{8}$ & 3.5626 & {$[-0.0061$} \\
\hline$b_{9}$ & -3.5182 & {$[-6.9482-0.0881]$} \\
\hline \multicolumn{3}{|c|}{$R^{2}=0.8835$} \\
\hline
\end{tabular}


The table shows, $R^{2}=0.8835$ the dependent variable y (incidence) of $88.35 \%$ determined by the model, $\mathrm{F}$ value exceeds the critical value of the F-test, $p=0.0300$, less than $\alpha=0.05$, so regression model was established.

Because the value of $R^{2}$ is not very ideal, and therefore we consider the possibility of a few of the five factors in the incidence of interactions on impact, so we improve the above model, the establishment of a new model is as follows:

$$
y=b_{1}+b_{2} x_{1}+b_{3} x_{2}+b_{4} x_{3}+b_{5} x_{4}+b_{6} x_{5}+b_{7} x_{1} x_{3}+b_{8} x_{3} x_{5}+b_{9} x_{2}^{2}+b_{10} x_{4}^{2}+b_{11} x_{5}^{2}
$$

We use MATLAB successive multivariate regression analysis program (see appendix) to solve the above model of regression coefficients give estimates and confidence intervals (confidence level $\alpha=0.05$ ), the results of the test statistic $R^{2}, F, p$ follows:

Table 7

\begin{tabular}{|c|c|c|}
\hline Parameter & Parameter estimates & Confidence Intervals \\
\hline$b_{1}$ & 1.3871 & {$\left[\begin{array}{ll}-1.9496 & 4.7238\end{array}\right]$} \\
\hline$b_{2}$ & -3.1452 & {$\left[\begin{array}{ll}-6.1968 & -0.0936\end{array}\right]$} \\
\hline$b_{3}$ & 5.2221 & {$\left[\begin{array}{ll}1.4924 & 8.9517\end{array}\right]$} \\
\hline$b_{4}$ & -2.469 & {$\left[\begin{array}{ll}-7.2337 & 2.2957\end{array}\right]$} \\
\hline$b_{5}$ & -7.9356 & {$\left[\begin{array}{ll}-10.8244 & -5.0469\end{array}\right]$} \\
\hline$b_{6}$ & 5.9298 & {$\left[\begin{array}{ll}1.7672 & 8.4928\end{array}\right]$} \\
\hline$b_{7}$ & 5.13 & {$\left[\begin{array}{ll}-0.3312 & 10.4233\end{array}\right]$} \\
\hline$b_{8}$ & 5.0461 & {$\left[\begin{array}{ll}-5.8704 & -0.3902\end{array}\right]$} \\
\hline$b_{9}$ & -3.1303 & {$\left[\begin{array}{ll}3.9969 & 10.7401\end{array}\right]$} \\
\hline$b_{10}$ & 7.3685 & {$\left[\begin{array}{ll}-14.2548 & -4.8109\end{array}\right]$} \\
\hline$b_{11}$ & -9.5329 & \\
\hline
\end{tabular}

Analysis: The table shows $R^{2}=0.9997$, the dependent variable y (incidence) of $99.97 \%$ determined by the model, $\mathrm{F}$ value far exceeds the threshold value F-test, $p<0.0002$, far less than $\alpha$, so this model is better.

This model residual analysis test results, obtained:

The results of the second regression residuals analysis chart:

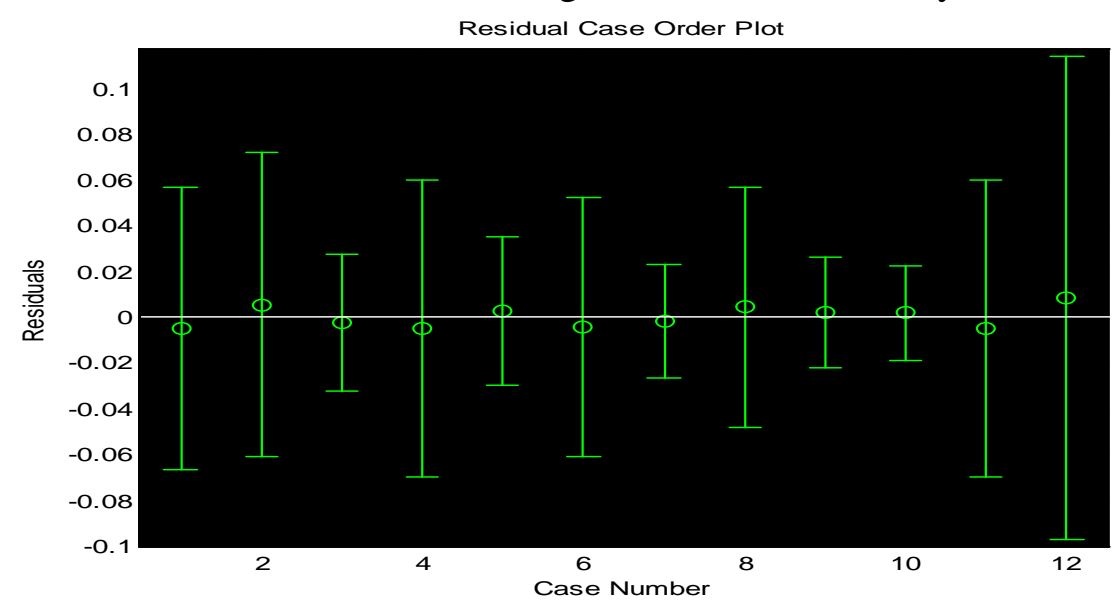

Residual analysis chart displays the selected data have been zero and no outliers, the model results are reasonable.

Based on the results of these two models are compared, there is a significant increase, and residual analysis results show that the improved model is more in line with reality than the previous model and 
can more accurately reflect the different average pressure, pressure difference, the average temperature, temperature, humidity and the relationship between the average incidence.

Popular to say that, Interactions average temperature, the average temperature and average humidity between the incidence of stroke was not significant; the interaction of the average pressure, pressure difference, temperature, average humidity, barometric pressure and average temperature average between the pressure difference of amplification, amplification of the temperature difference, the amplification of the average humidity affect the incidence of stroke is significant. With the function expressed as:

$$
\begin{aligned}
y= & 1.3871-3.1452 x_{1}+5.2221 x_{2}-2.4690 x_{3}-7.9356 x_{4}+5.9298 x_{5}+5.13 x_{1} x_{3} \\
& +5.0461 x_{3} x_{5}-3.1303 x_{2}^{2}+7.3685 x_{4}^{2}-9.2329 x_{5}^{2}
\end{aligned}
$$

In accordance with the results of (a), (b), we are proposed early warning and intervention advice.

1, for the three outcomes (a) obtained: male incidence rate (53.93 percent) than women (46.07\%) large; people (39.60\%) 75-89 years of age most vulnerable to disease, followed by 60-74 year-olds ( $39.31 \%)$; the incidence of farmers (64.44\%) Highest workers ranked second (14.79\%), the incidence of retirees (13.62\%), followed by;

For analysis, so-called high-risk groups are a high incidence of people. We can see that:

The incidence for the impact of gender is an objective reality, we can not intervene.

For the second result, we can take some preventive measures to reduce or even avoid the occurrence of stroke. For over 60 years, especially the elderly and should pay more attention and the need for prevention through the following programs:

(1) Periodic medical examinations, to understand whether the abnormal cardiovascular function was found to be active after the exception therapy;

(2) Maintain a good mood thinking, adherence to the law of the biological clock; reasonable diet, the elderly should eat high-fat, high-cholesterol as a diet should be rich in vitamins and vegetarian foods. This prevents excessive blood lipid, prevent arteriosclerosis, reduce the possibility of thrombosis;

(3) emphasis on threatened, if there is blood pressure, high blood lipids and other phenomenon, should go to regular hospital for examination.

For the third result, the peasants, the workers, the higher the incidence of retirees, so for these high-risk groups, should:

(1) Develop a healthy, scientific habits;

(2) Note that the abnormal changes in the body, regular medical examinations.

2. For the results of (b):

$$
\begin{aligned}
y= & 1.3871-3.1452 x_{1}+5.2221 x_{2}-2.4690 x_{3}-7.9356 x_{4}+5.9298 x_{5}+5.13 x_{1} x_{3} \\
& +5.0461 x_{3} x_{5}-3.1303 x_{2}^{2}+7.3685 x_{4}^{2}-9.2329 x_{5}^{2}
\end{aligned}
$$

Description Average pressure, pressure difference, temperature, average humidity, barometric pressure and average temperature average interaction between the pressure difference of amplification, amplification of the temperature difference, the amplification of the average humidity affect the incidence of stroke was significant .

Therefore, we propose the following recommendations:

(1) In every winter, high pressure, low humidity, should keep warm, alert, reduce adverse stimuli external environment and to improve their ability to adapt.

(2), in the annual seasonal temperature, pressure difference is large, it should pay attention to changes in weather conditions, to take timely measures to reduce the possibility of stroke induced by environmental factors.

3, promotion

Sales of the goods, the salary problem of company personnel, chemical catalytic reaction 


\section{References}

[1] H.Y.Xiao, Practical mathematical modeling and software application,Northwestern Polytechnical University Press, 11(2008).

[2] Q.Y.Jiang, Mathematical model t, Higher Education Publisher Press. 8(2003).

[3] Information on http://www.jhhospital.com/wsfw/ShowArticle.asp?ArticleID=657

[4] Information on http://www.365heart.com/show/79521.shtml

[5] Information on http://zx.wuxi.gov.cn/web101/xwzx/dtxx/tagz/taxb/816008.shtml

[6] Information on http://baike.baidu.com/view/349682.htm 